\title{
INFLUÊNCIA DO TIPO DE AGITAÇÃO NA REMOÇÃO DE CROMO DE EFLUENTES CONTAMINADOS UTILIZANDO UMA CULTURA MISTA
}

\author{
P.P.P. FILHO ${ }^{1}$, N. M. TERRA ${ }^{1}$, M.M. DE RESENDE ${ }^{1}$, V. L. CARDOSO ${ }^{1}$ \\ ${ }^{1}$ Universidade Federal de Uberlândia, Faculdade de Engenharia Química \\ E-mail para contato: mresende@feq.ufu.br
}

\begin{abstract}
RESUMO -A contaminação de efluentes com cromo, um metal pesado, é preocupante, pois o cromo é considerado extremamente tóxico e também cancerígeno. O uso de microrganismos no tratamento de efluentes contendo cromo é interessante devido a potencialidade que estes seres apresentam em tolerar e resistir a essa toxicidade. Este trabalho teve como objetivo avaliar a influência de duas formas de agitação, mecânica e magnética, no tratamento de efluentes contaminados com cromo. Foi utilizado dicromato de potássio $\left(\mathrm{K}_{2} \mathrm{Cr}_{2} \mathrm{O}_{7}\right)$ como fonte de cromo, e uma cultura mista como fonte de microrganismo em um reator batelada com recirculação do efluente. Os resultados obtidos em ambas as formas de agitação foram similares quanto à remoção de cromo total.
\end{abstract}

\section{INTRODUÇÃO}

As contaminações que envolvem o uso de metais pesados nos recursos hídricos e do solo são uma das grandes preocupações de agências ambientais (Hong et al., 2010). O termo "metal pesado" é designado a um grupo de elementos, incluindo metais, semimetais e não metais que possuem número atômico maior do que 20 ou peso específico maior que $5 \mathrm{~g} / \mathrm{cm}^{3}$ (Malavolta, 1994). O cromo é introduzido no ambiente por meio de efluentes industriais, que são descartados pela indústria de processamento de madeira, curtimento de couro, fabricação de aço, tintas e outros. $O$ cromo proporciona resistência à degradação em peles de animais para obtenção do couro. O composto aplicado nesse processo é o sulfato de cromo III $\mathrm{Cr}_{2}\left(\mathrm{SO}_{4}\right) \cdot \mathrm{xH}_{2} \mathrm{O}$, comumente referido como sal de cromo (Mota, 2001).

Os estados de oxidação do cromo encontrados no meio ambiente são o $\mathrm{Cr}(\mathrm{VI})$ e Cr (III), no qual o cromo hexavalente é significativamente mais tóxico que o cromo trivalente devido à sua alta solubilidade e grande mobilidade no ambiente (Sufia, 2010). A resolução do CONAMA (Conselho Nacional do Meio Ambiente) no 397, de 3 de abril de 2008, estabelece as condições e padrões de lançamento de efluentes de qualquer fonte poluidora, estabelecendo que os efluentes desta natureza somente poderão ser lançados, direta ou indiretamente, nos corpos receptores quando os teores de cromo hexa e trivalente forem inferiores a $0,1 \mathrm{mg} / \mathrm{L} \mathrm{e} 1,0 \mathrm{mg} / \mathrm{L}$, respectivamente.

Além do baixo impacto ambiental, os processos de tratamento biológicos despertam grande interesse de pesquisadores, pois eles reproduzem os fenômenos que 


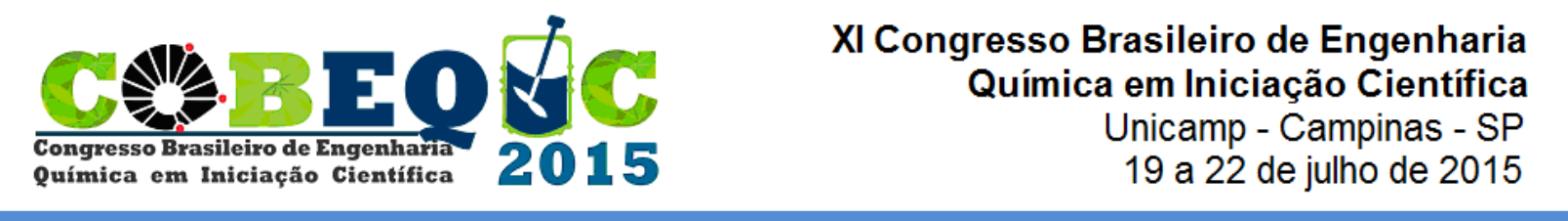

acontecem na natureza. Estudos comprovam que certas espécies de microrganismos transformam o cromo hexavalente em uma forma de menor toxidade, ou seja, Cr (III), para que o seu próprio meio de cultura seja menos agressivo. (Camargo et al., 2005; Pal e Paul, 2005).

A agitação proporciona um aumento no contato dos microganismos com o efluente a ser tratado durante a fase da reação (Angenent e Dague, 1995; Ndon e Dague, 1997; Zaiat et al., 2001). A intensidade da agitação não deve ser muito alta, devido à fragilidade os microrganismos utilizados. Assim, este estudo tem como objetivo avaliar a influência do tipo de agitação na remoção de cromo hexavalente utilizando uma cultura mista de bactérias em um reator em batelada.

\section{METODOLOGIA UTILIZADA}

\subsection{Micro-organismos}

Para realização deste trabalho foi utilizada uma cultura mista obtida a partir do lodo da indústria de curtume, que já se encontrava no banco de microrganismos do Laboratório da Faculdade de Engenharia Química. Esta cultura mista foi mantida no meio de cultura de composição: $\mathrm{NH}_{4} \mathrm{Cl} 1$ g.L $\mathrm{L}^{-1} ; \mathrm{K}_{2} \mathrm{HPO}_{4}$ 0,5 g.L $\mathrm{L}^{-1} ; \mathrm{MgSO}_{4} \cdot 7 \mathrm{H}_{2} \mathrm{O}$ 0,2 g.L ${ }^{-1} ; \mathrm{FeSO}_{4} \cdot 7 \mathrm{H}_{2} \mathrm{O}$ 0,001 g.L $\mathrm{L}^{-1}$; $\mathrm{CaCl}_{2} \cdot 2 \mathrm{H}_{2} \mathrm{O}$ 0,001 g.L ${ }^{-1}$; Extrato de Levedura 3 g.L. ${ }^{-1} ; \mathrm{CH}_{3} \mathrm{COONa} .3 \mathrm{H}_{2} \mathrm{O} 6$ g.L ${ }^{-1}$, com renovação do meio de cultura a cada dois dias.

\subsection{Fonte de Cr (VI)}

A fonte de cromo hexavalente utilizada foi o dicromato de potássio $\left(\mathrm{K}_{2} \mathrm{Cr}_{2} \mathrm{O}_{7}\right)$ P.A. marca Vetec, na proporção de $2,82 \mathrm{mg} / \mathrm{L}$ de $\mathrm{K}_{2} \mathrm{Cr}_{2} \mathrm{O}_{7}$ para obter $1 \mathrm{mg} / \mathrm{L}$ de $\mathrm{Cr}$ (VI). Os microrganismos foram centrifugados, ressuspensos em meio de cultura e $\mathrm{Cr}$ (VI) na concentração inicial de 150 $\mathrm{mg} / \mathrm{L}, \mathrm{pH} 6$ e colocados em dois reatores batelada, sendo que o efluente era bombeado por uma tubulação que retornava para o reator. A diferença dos reatores está na agitação, sendo um com agitação mecânica e outro com agitação magnética.

\subsection{Cromo total}

A concentração de cromo total foi determinada por espectrometria de absorção atômica em chama, marca Shimadzu, modelo AA-7000.

\section{RESULTADOS}

Estudou-se a influência do tipo de agitação na remoção do cromo pela cultura mista. Este teste foi proposto, pois ao utilizar a agitação mecânica observou-se o prendimento e acúmulo do inóculo na pá utilizada, conforme a Figura 2.1, o que levou a suspeitar que parte das células não ficaria em contato direto com o efluente e isto poderia comprometer a eficiência do processo. 


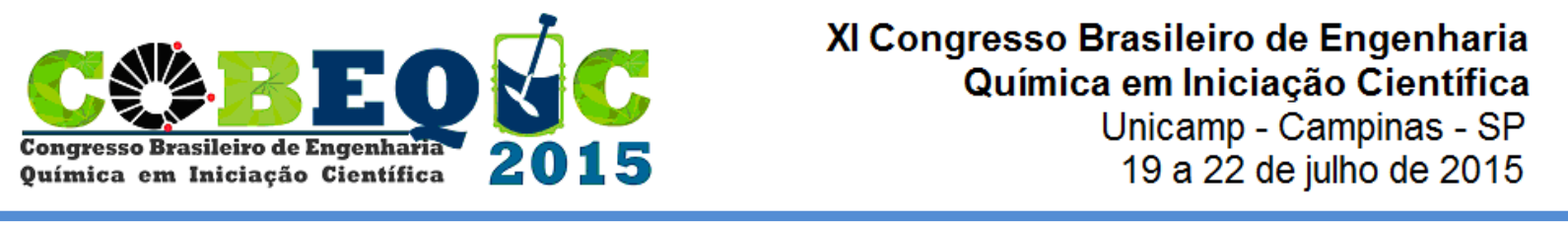

Figura 2.1 -Acúmulo de células na pá de agitação mecânica.

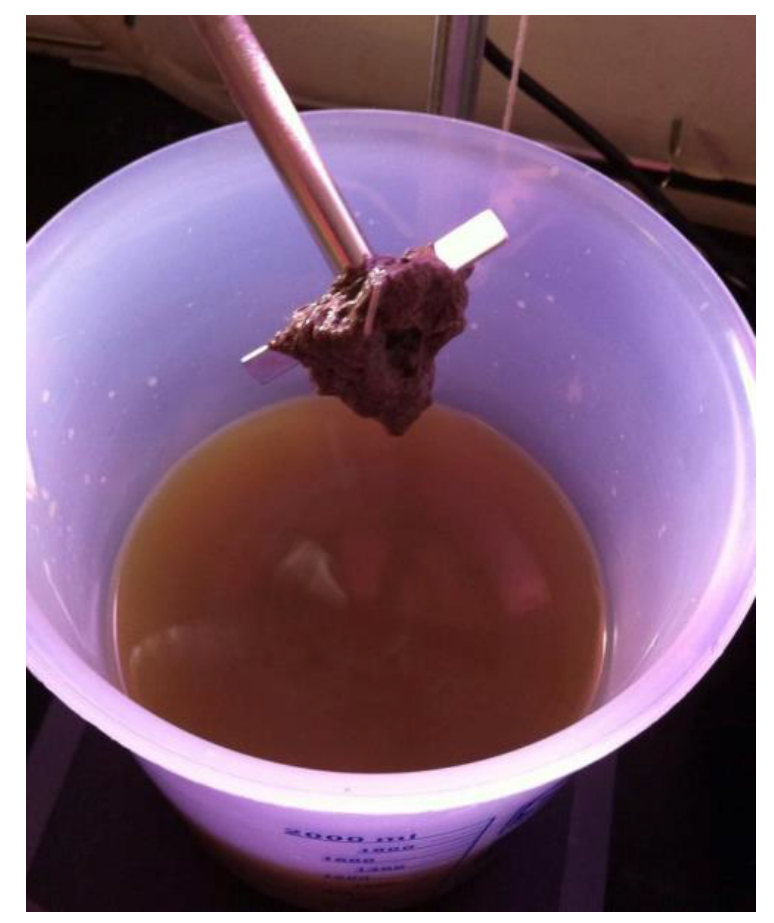

Os resultados deste teste comparativo estão apresentados graficamente pela Figura 2.2.

Figura 2.2 - Perfil de remoção de cromo total em função do tempo para agitação mecânica e magnética, com $\mathrm{Cr}_{0}=150 \mathrm{mg} / \mathrm{L}$.

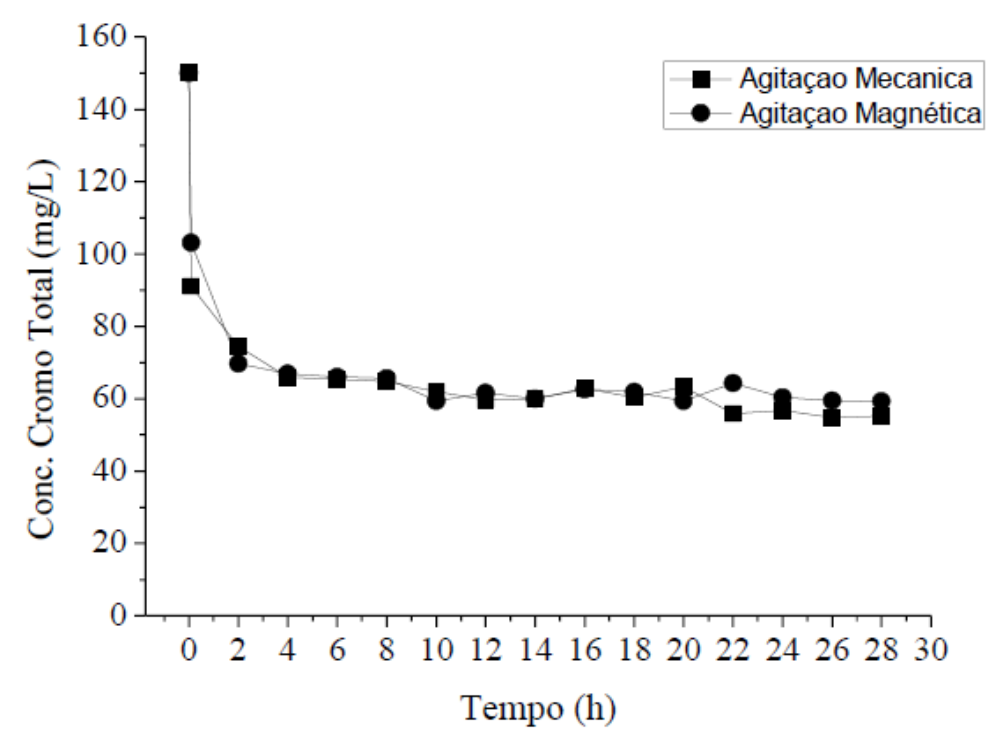

De acordo com a Figura 2.2, observa-se que houve o mesmo comportamento de remoção em ambos os tipos de agitação adotados. Portanto, a mesma quantidade de cromo presente no efluente foi removida, independentemente do tipo de agitação 
escolhido. Neste teste, observou-se apenas a remoção de cromo, não levando em consideração a sobrevivência dos microrganismos. Como a agitação magnética possui maior atrito com as células poderia levar ao rompimento da célula e,consequentemente, a morte destas, e assim ocorreria apenas a remoção pelo processo de biossorção, ou seja, retenção do cromo no microrganismo mesmo que ele não esteja vivo.

\section{CONCLUSÃO}

Ao trabalhar com elevada concentração inicial do contaminate cromo (150 $\mathrm{mg} / \mathrm{L}$ ), foi observado que independe do tipo de agitação utilizada, houve nas primeiras horas uma maior remoção de cromo total do meio, se estabilizando nas demais horas.

$\mathrm{Na}$ agitação magnética, há um maior atrito das células levando as células a se romperem, consequentemente, ocasionando a morte das mesmas. Neste trabalho, não foi avaliado o possível rompimento da célula que poderia ocorrer ao utilizar este tipo de agitação. Conclui-se também que a remoção de cromo total do efluente apresentou os mesmo níveis de remoção, independente do tipo de agitação utilizado.

\section{REFERÊNCIAS BIBLIOGRÁFICAS}

ANGENENT, L.T.; DAGUE, R. R. (1995). A laboratory- scale comparison of the $U A S B$ and ASBR process. In: 50th Purdue Industrial. Wastewater Conference Proceedings, Ann Arbor Press, Chelsea, p. 365-377.

CAMARGO, F.A.O., OKEKE, B.C., BENTO, F.M., FRANKENBERGER, W.T. Diversity of chromium-resistant bacteria isolated from soils contaminated with dichromate, Appl. Soil Ecol. 29, 193-202, 2005.

HONG, Z, et al. Hexavalent chromium removal from aqueous solution by algal bloom residue derived activated carbon: equilibrium and kinetic studies.J Hazard Mater 2010; 181: 801-8.

MALAVOLTA, E. Fertilizantes e seu impacto ambiental: micronutrientes e metais pesados, mitos, mistificações e fatos. São Paulo: ProduQuímica, 1994. 153p.

MOTA, J. S. Eco-eficiência: avaliação de sustentabilidade de industria do couro no MS. 2001. Dissertação (Mestrado em Desenvolvimento Sustentável) - UnB, Brasília. 2001.

NDON, U.J.; DAGUE, R.R. (1997). Effects of temperature and hydraulic retention time on anaerobic sequencing batch reactor treatment of low-strenght wastewater. Water Research, 31, 2455-2466. 
SUFIA, H. Removal of chromium hexavalent ion from aqueous solutions using biopolymer chitosan coated with poly 3-methyl thiophene polymer. J Hazard Mater 2010; 181:474-9.

ZAIAT, M.; RODRIGUES, J.A.D.; RATUSZNEI, S.M.; CAMARGO, E.F.M.; BORZANI, W. (2001). Anaerobic sequencing batch reactors for wastewater treatment: a developing technology.Applied Microbiology and Biotechnology, 55, 29-35. 